\title{
CORROSION RESISTANCE OF ESD COATINGS BEFORE AND AFTER LASER PROCESSING
}

\author{
${ }^{1}$ Norbert RADEK, ${ }^{2}$ Jacek PIETRASZEK, ${ }^{3}$ tukasz J. ORMAN \\ ${ }^{1}$ Kielce University of Technology, Faculty of Mechatronics and Mechanical Engineering, Kielce, Poland, EU, \\ norrad@tu.kielce.pl \\ ${ }^{2}$ Cracow University of Technology, Institute of Applied Informatics, Cracow, Poland, EU, \\ jacek.pietraszek@mech.pk.edu.pl \\ ${ }^{3}$ Kielce University of Technology, Faculty of Environmental, Geomatic and Energy Engineering, Kielce, \\ Poland, EU, orman@tu.kielce.pl
}

https://doi.org/10.37904/metal.2020.3575

\begin{abstract}
A number of modern surface processing methods use an energy flux. The examples include electro-spark deposition (ESD) and laser processing (LP). Electro-spark deposition is a cheap high-energy process. The method was first used in the USSR in the 1940s almost simultaneously with the destructive electrical discharge machining. The ESD technique was studied intensively in the 1960s. In the next decade, it was commonly applied to deposit hard-melting materials on selected metals and alloys, mainly steel. Polish scientists became interested in electro-spark alloying of coatings as early as in the 1980s. Electro-spark deposited coatings have some disadvantages but these can be easily eliminated. One of the methods is laser processing; a laser beam is used for surface polishing, surface geometry formation, surface sealing or for homogenizing the chemical composition of the deposited coatings. The corrosion resistance of C45 steel coated with WC-Cu electro-spark technique and the influence of the laser treatment process on the properties of the coatings were examined in a chloride environment. The coatings were deposited by means of an EIL-8A. The laser processing was performed with an Nd:YAG, BLS 720 system. The studies were conducted using WC-Cu electrodes produced by the powder metallurgy route. The potentiodynamic polarization technique was mainly used. Scanning electron microscope (SEM) was employed for the observation the surface of materials. The structure of coatings was dependent on the composition of electrospark electrodes. It is assumed that the use of lasermodified electro-spark deposited coatings will increase the applications of using relatively inexpensive materials in areas requiring special alloys, for example, sealing technology, precision products or surfaces in sliding contact.
\end{abstract}

Keywords: ESD coatings, laser processing, corrosion resistance, microstructure, surface topography

\section{INTRODUCTION}

By applying new engineering materials or protective coatings, it is possible to improve the functional properties of machine parts so that they are resistant to corrosion, abrasion and erosion, and possess high fatigue strength. The new materials, for instance, alloy steels, are usually costly, which is undesirable, because the higher the cost of the material, the higher the price of a finished product. However, if an element is to be subjected to high loads, then strength rather than cost is a primary factor.

A number of modern surface processing methods use an energy flux. The examples include electro-spark alloying (ESA) and laser beam machining (LBM).

The processes of coating formation on metal parts including electro-spark deposition involve mass and energy transport accompanied by chemical, electrochemical and electrothermal reactions [1]. Today, different electro- 
spark deposition techniques are used; they are suitable for coating formation and surface microgeometry formation [2-4].

Coatings produced by electro-spark deposition are applied to (a) to protect new elements or to (b) to recover the properties of worn elements. The electro-spark deposition coating is characterized by a non-etching structure. The surface layer is constituted in environment of local high temperature and high pressure. Electromachining is characterized by [5]:

- $\quad$ shock wave pressure coming from electric spark is (2-7)·103 GPa,

- temperature reaching $(5-40) \cdot 103^{\circ} \mathrm{C}$.

As electro-spark coatings are reported to be resistant to wear and corrosion, they can be applied to e.g. ship propeller components, casting moulds, fuel supply system components or exhaust system components.

Electro-spark deposited coatings have some disadvantages but these can be easily eliminated. One of the methods is laser beam machining; a laser beam is used for surface polishing, surface geometry formation, surface sealing or for homogenizing the chemical composition of the deposited coatings [6-8].

The work discusses the properties of electro-spark deposited WC-Cu coatings subjected to laser treatment. The properties were established basing on the results of a microstructure analysis, corrosion resistance tests and surface geometric structure measurements. In addition to similar issues (e.g. [9]), the results obtained may be of interest to other materials science researchers e.g. steel treatment [10], light alloys [11,12] or conductivity modifications [13]. It can also be inspiring to improve and develop theoretical methods, in the field of stress analysis in a modified surface layer [14] and also image analysis [15-17] of this layer.

\section{MATERIALS AND TREATMENT PARAMETERS}

The working electrode (a stationary) was made from C45 carbon steel. The elemental composition of the steel was as follows (wt.\%): C: $0.42-0.50, \mathrm{Mn}: 0.50-0.80$, Si: $0.10-0.40, \mathrm{P}: 0.04, \mathrm{~S}: 0.04$.

An EIL-8A pulse spark generator was used to deposit the coatings on the steel surface. The operating parameters of the generator were determined experimentally: $0.7 \mathrm{~A}, 230 \mathrm{~V}$ and $150 \mu \mathrm{F}$ capacitors. Cylindrical electrodes, $5 \mathrm{~mm}$ in diameter and $10 \mathrm{~mm}$ in height were used. They were produced by means of the impulseplasma sintering method in a graphite matrix of tungsten carbide (particle diameter $\sim 0.2 \mu \mathrm{m}$ ) and metallic copper (particle diameter $\sim 0.04 \mu \mathrm{m}$ ) nanopowders at a temperature of $950{ }^{\circ} \mathrm{C}$, under a pressure of $40 \mathrm{MPa}$. The nanopowders were mixed in the following proportions: $75 \% \mathrm{WC}$ and $25 \% \mathrm{Cu}, 50 \% \mathrm{WC}$ and $50 \% \mathrm{Cu}, 25 \%$ WC and $75 \% \mathrm{Cu}$. The following designations were given to the particular electrodes: WC25-Cu75, WC50Cu50 and WC25-Cu75. Then, the coatings were treated with an Nd:YAG laser (impulse mode) model BLS 720. The samples with electro-spark deposited coatings were laser-modified using the following parameters: spot diameter $\mathrm{d}=0.7 \mathrm{~mm}$, power $\mathrm{P}=60 \mathrm{~W}$, laser beam velocity $v=250 \mathrm{~mm} / \mathrm{min}$, nozzle-workpiece distance $\Delta f=6 \mathrm{~mm}$, pulse duration $t_{i}=0.4 \mathrm{~ms}$, pulse repetition frequency $f=50 \mathrm{~Hz}$, beam shift jump $S=0.4 \mathrm{~mm}$, nitrogen gas shield $Q=25 \mathrm{l} / \mathrm{min}$.

\section{EXPERIMENTAL RESULTS AND DISCUSSIONS}

\subsection{Microstructure analysis}

A microstructure analysis was conducted for WC-Cu coatings before and after laser treatment using a scanning electron microscope Joel JSM-5400.

Figure 1 shows the microstructure of an ESD WC-Cu coating. It is clear that the thickness of the obtained layer varied from 36 to $60 \mu \mathrm{m}$, whereas the heat affected zone (HAZ) ranged from 20 to $30 \mu \mathrm{m}$ into the substrate. Figure 1 also reveals a clear boundary between the coating and the substrate and pores within the 
coating. The ESD WC-Cu coatings were modified by the laser treatment, which caused changes in their composition. The laser treatment homogenizes the coating chemical composition, causes structure refinement, and crystallization of non-equilibrium phases due to the occurrence of temperature gradients and high cooling rates.

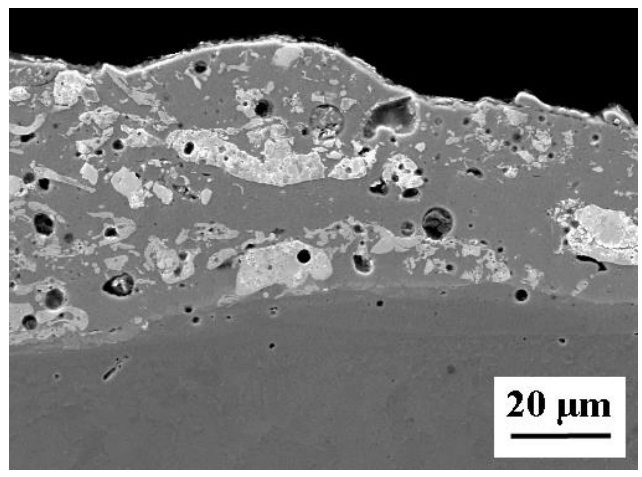

Figure 1 WC50-Cu50 coating microstructure after electro-spark alloying

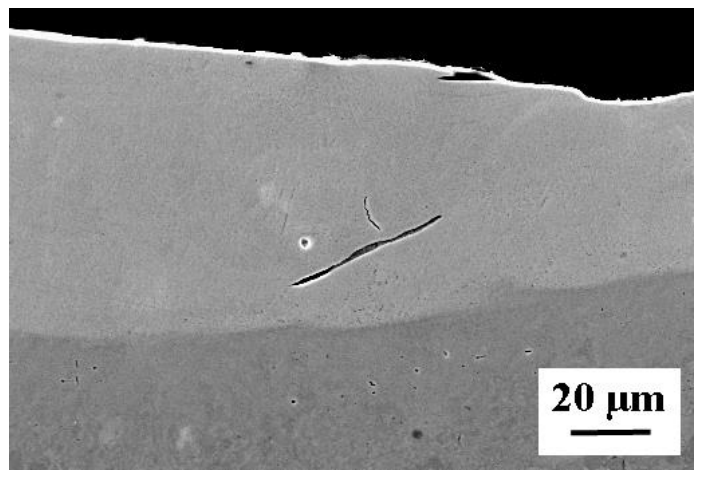

Figure 2 Microstructure of the electro-spark alloying WC50-Cu50 coating after treatment with an Nd:YAG laser

The laser-modified outer layer does not possess microcracks or pores (Figure 2). There is no discontinuity of the coating-substrate boundary. The thickness of the laser-treated WC-Cu coatings ranges from 40 to $62 \mu \mathrm{m}$. Moreover, the heat affected zone (HAZ) is in the range of 25 to $35 \mu \mathrm{m}$, and the content of carbon in the zone is higher.

\subsection{Corrosion resistance tests}

Polarization measurements were made using a potentiostat/galvanostat PGSTAT 128N (AutoLab) equipment to investigate the influence of the composition of the coating (WC-Cu) on the electrochemical corrosion of C45 steel. The polarization curves were recorded in a $1 \mathrm{M} \mathrm{Cl}^{-}$acid solution. The following reagents were used to make the solutions: FLUKA analytical grade sodium chloride $(\mathrm{NaCl})$ and $\mathrm{POCH}$ analytical grade hydrochloric acid $(\mathrm{HCl})$. Water, which was distilled three times, was used as a solvent. The corrosive environment (supporting electrolyte) was obtained by mixing the sodium chloride $(0.8 \mathrm{M})$ and hydrochloric acid $(0.2 \mathrm{M})$, so the concentration of $\mathrm{Cl}$ - ions was $1 \mathrm{M}$ and the $\mathrm{pH}$ was 1.5 . Measurements were carried out under a potential range between -800 and $-50 \mathrm{mV}$ whereas the potential change rate was $1 \mathrm{mV} \mathrm{s}^{-1}$. Polarization curves were used to designate the corrosion potential ( $\left.\mathrm{E}_{\text {corr }}\right)$ and corrosion current density (jcorr).

The polarization curves for $\mathrm{C} 45$ steel, coated by means of ESD using tungsten carbide (WC) and copper (Cu) mixed in various proportions are shown in Figure 3.

Polarization curves were used to determine the various parameters of steel corrosion, which have been summarized in Table 1. As the copper content in the nanopowder mixture used in the deposition of WC-Cu coatings onto the surface of steel increased, the corrosion potential shifted slightly (ca. $20 \mathrm{mV}$ ) towards positive values, while the corrosion current density decreased. Consequently, in the case of the WC25-Cu75 coating, the corrosion rate is approximately three times slower as compared to steel, which has not been coated with WC-Cu at all. An addition of copper to the nanopowder mixture clearly increases the corrosion resistance of steel. It seems that copper improves the tightness of the tungsten carbide layer, making it difficult for the aggressive chloride solution to contact the steel surface.

Figure 4 shows the Tafel plots for the WC50-Cu50 coating on the C45 steel surface prior to (a) and after the laser treatment (b). Potentiodynamic polarization curves were used to determine selected corrosion parameters, which have been summarized in Table 1. 


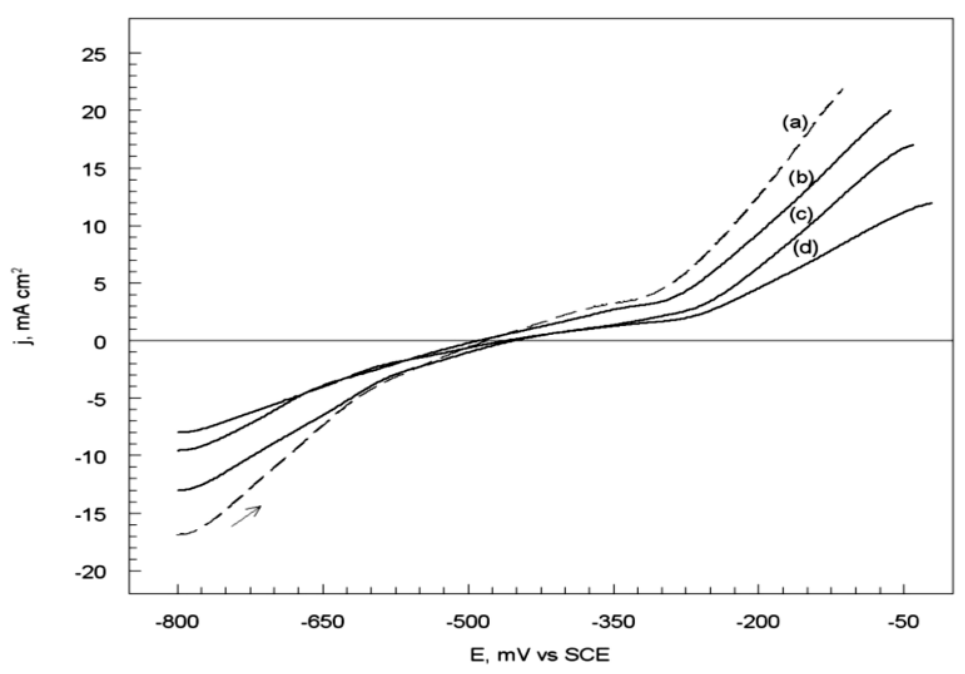

Figure 3 Polarization curves for $\mathrm{C} 45$ steel. Solution containing $1 \mathrm{M} \mathrm{Cl}$. Electrode surface: (a) absence of coating, (b) WC75-Cu25, (c) WC50-Cu50, and (d) WC25-Cu75, dE/dt $1 \mathrm{mV} \mathrm{s}^{-1}$

Table 1 Corrosion parameters and corrosion rate of $\mathrm{C} 45$ steel in absence and presence of WC-Cu coating in a solution containing $1 \mathrm{M} \mathrm{Cl}^{-}$

\begin{tabular}{|c|c|c|c|}
\hline Material & $\boldsymbol{E}_{\text {corr }}(\mathbf{m V})$ & $j_{\text {corr }}\left(\mathbf{m A} \cdot \mathbf{c m}^{-2}\right)$ & $\boldsymbol{k}_{\text {corr }}(\mathbf{m m} / \mathbf{y e a r})$ \\
\hline Absence & -480 & 1.10 & 12.8 \\
\hline WC75-Cu25 & -487 & 0.80 & 9.3 \\
\hline WC50-Cu50 & -451 & 0.53 & 6.1 \\
\hline WC25-Cu75 & -459 & 0.40 & 4.6 \\
\hline WC75-Cu25+laser & -360 & 0.23 & 5.8 \\
\hline WC50-Cu50+laser & -402 & 0.17 & 3.7 \\
\hline WC25-Cu75+laser & -410 & 0.15 & 1.4 \\
\hline
\end{tabular}

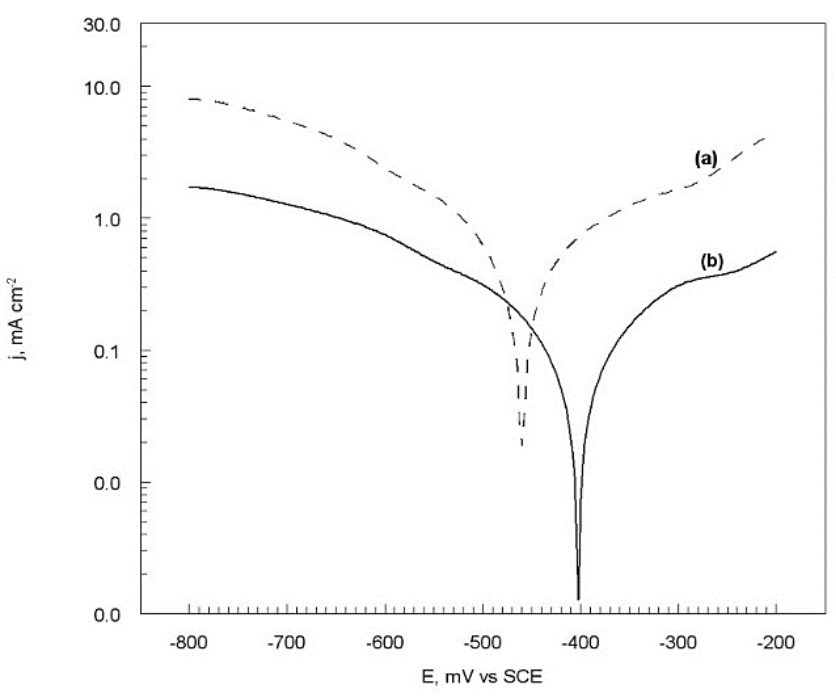

Figure 4 Tafel plots for the $\mathrm{C} 45$ carbon steel in $1 \mathrm{M} \mathrm{Cl}^{-}$.The WC50-Cu50 coating: (a) before, (b) after laser treatment 
The obtained results indicate that in the case of the laser treated coating the corrosion potential was shifted by about $50 \mathrm{mV}$ whereas the corrosion current density was decreased be a factor of three compared to the untreated coating. It implies that the corrosion resistance of WC-Cu coatings on steel has been markedly improved by the laser treatment (Table 1). This can be attributed mainly to the improvement of the WC-Cu condition after laser irradiation.

As a result of the laser treatment different oxides and fine grains form on the surface of coating, which leads to different corrosion characteristics. The compact oxide layer provides an effective barrier to protect the coating on the carbon steel against corrosion in an aggressive environment of chlorides.

\subsection{Measurements of the surface geometric structure}

Surface geometric structure (SGS) of the WC-Cu coatings was measured at the Laboratory for Measurement of Geometric Quantities of the Kielce University of Technology using a TALYSURF CCI equipment. Threedimensional surfaces and their analysis using the software TalyMap Platinium allowed to thoroughly know the geometric structure of the surface tested. Figure 5 presents an example three-dimensional surface topography measurement of the WC50-Cu50 coatings after and before laser treatment.
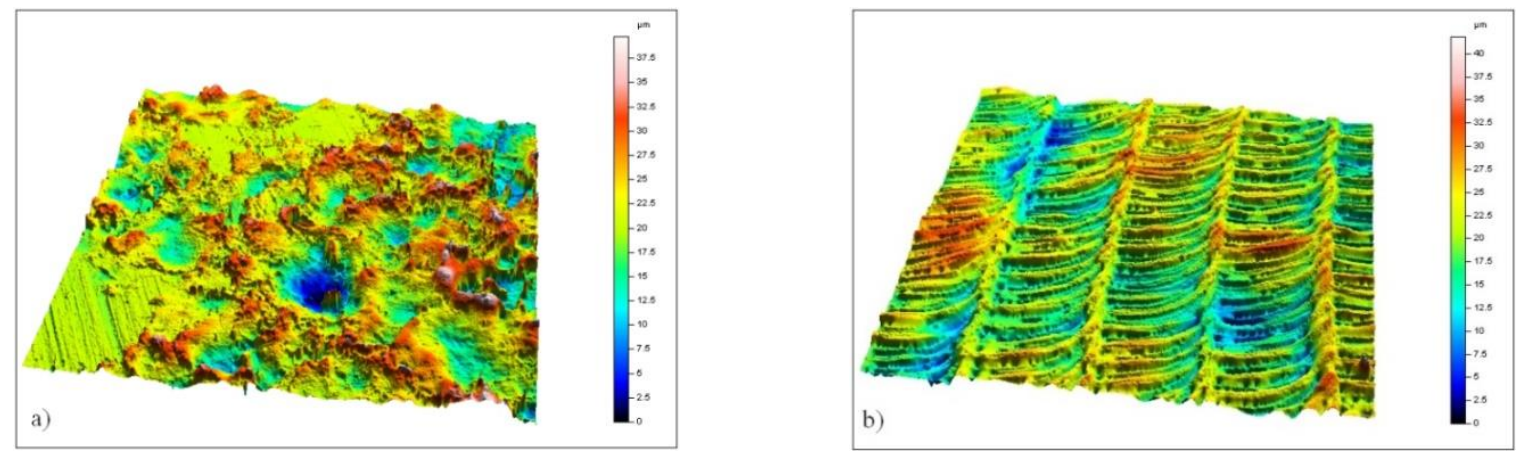

Figure 5 Specimen surface topography: a) before laser treatment, b) after laser treatment

A greater value of the mean arithmetic deviation of surface roughness $S a=3.98 \mu \mathrm{m}$, a basic amplitude parameter in the quantitative assessment of the state of the surface under analysis, was recorded for the specimen after the laser treatment, for the specimen before the laser treatment the value of this parameter was be almost $5 \%$ higher. Laser processing caused a slight decrease in the $S a=3.80 \mu \mathrm{m}$ parameter, which is very beneficial for surface quality.

A similar tendency is observed for the root mean square deviation of surface roughness Sq. Complementary information on how the surface of examined elements is shaped is provided by amplitude parameters, namely the coefficient of skewness (asymmetry) Sku and the coefficient of concentration (kurtosis) Ssk. Those parameters are sensitive to occurrence of local hills or valleys, and also defects on the surface. The parameter Ssk has a positive value for both specimens, the value is close to zero for the specimen before treatment, which indicates the symmetrical location of the distribution of ordinates with respect to the mean plane. The values of kurtosis that were obtained are close to $S k u=3$, which indicates that the distribution of ordinates for both specimens is close to normal distribution.

\section{CONCLUSIONS}

Finally, it can be concluded that:

- A concentrated laser beam can be effective in modifying the state of the outer layer of electro-spark coatings and thus can modify their functional properties.

- $\quad$ Laser irradiation of coatings resulted in the healing of micro-cracks and pores. 
- $\quad$ Parameters of surface geometric structure of electro-spark coatings have lower values when compared with SGS parameters of coatings after laser treatment.

- Laser radiation causes an improvement in the functional properties of the electro-spark deposited WCCu coating, i.e. they exhibit higher resistance to corrosion.

- Coatings of that type can be applied to sliding friction pairs and can operate as protective coatings.

\section{REFERENCES}

[1] GALINOV, I. and LUBAN, R. Mass transfer trends during electrospark alloying. Surf. Coat. Technol. 1996. vol. 79, pp. 9-18.

[2] SALMALIYAN, M., GHAENI, F.M. and EBRAHIMNIA, M. Effect of electro spark deposition process parameters on WC-Co coating on H13 steel. Surf. Coat. Technol. 2017. vol. 321, pp. 81-89.

[3] SHEVEYKO, A., KUPTSOV, K.A., KIRYUKHANTSEV-KORNEEV, P.V., LEVASHOV, E.A. and SHTANSKY, D.V Hybrid technology combining vacuum electrospark alloying, cathodic arc evaporation, and magnetron sputtering for the deposition of hard wear-resistant coatings. Russ. J. Non-Ferrous Met. 2019. vol. 60, pp. 598-607.

[4] CAO, G., ZHANG, X., TANG, G. and MA, X. Microstructure and Corrosion Behavior of $\mathrm{Cr}$ Coating on M50 Steel Fabricated by Electrospark Deposition. J. Mater. Eng. Perform. 2019. vol. 28, pp. 4086-4094.

[5] MIERNIKIEWICZ, A. Doświadczalno-teoretyczne podstawy obróbki elektroerozyjnej EDM. Wyd. Politechniki Krakowskiej, Kraków, 1999.

[6] RADEK, N., WAJS, E. and LUCHKA, M. The WC-Co electrospark alloying coatings modified by laser treatment. Powder Met. Met. Ceram. 2008. vol. 47, pp. 197-201.

[7] PIETRASZEK, J., RADEK, N. and BARTKOWIAK, K. Advanced statistical refinement of surface layer's discretization in thecase of electro-spark deposited carbide-ceramic coatings modified bya laser beam. Solid State Phenom. 2013. vol. 197, pp. 198-202.

[8] GĄDEK-MOSZCZAK, A., RADEK, N., WROŃSKI, S. and TARASIUK, J. Application the 3D image analysis techniques for assessmentthe quality of material surface layer before and after laser treatment. Adv. Mater. Res.Switz. 2014. vol. 874, pp. 133-138.

[9] LIPINSKI, T. and KARPISZ, D. Corrosion rate of 1.4152 stainless steel in a hot nitrate acid. In METAL 2019: 28 $8^{\text {th }}$ Int. Conf. Metallurgy and Materials. Ostrava, TANGER, 2019, pp. 1086-1091.

[10] LIPINSKI, T. and WACH, A. Influence of outside furnace treatment on purity medium carbon steel. In METAL

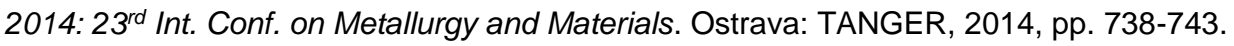

[11] KORZEKWA, J., SKONECZNY, W., DERCZ, G. and BARA, M. Wear Mechanism of $\mathrm{Al}_{2} \mathrm{O}_{3} / \mathrm{WS}_{2}$ with PEEK/BG Plastic. Journal of Tribology-Transactions of the ASME. 2014. vol. 136, art. 011601.

[12] BARA, M., KMITA, T. and KORZEKWA, J. Microstructure and Properties of Composite Coatings obtained on Aluminium Alloys. Arch. Metall. Mater. 2016. vol. 61, pp. 1107-1112.

[13] SKULSKI, R., WAWRZALA, P., KORZEKWA, J. and SZYMONIK, M. The Electrical Conductivity of PMN-PT Ceramics. Arch. Metall. Mater. 2009. vol. 54, pp. 935-941.

[14] SYGUT, P., KLIMECKA-TATAR, D. and BORKOWSKI, S. Theoretical analysis of the influence of longitudinal stress changes on band dimensions during continuous rolling process. Arch. Metall. Mater. 2016. vol. 61, pp.183188.

[15] GADEK-MOSZCZAK, A. History of stereology. Image Analysis \& Stereology. 2017. vol. 36, pp. 151-152.

[16] GADEK-MOSZCZAK, A. and MATUSIEWIC, P. Polish stereology - a historical review. Image Analysis \& Stereology. 2017. vol. 36, pp. 207-221.

[17] WOJNAR, L., GADEK-MOSZCZAK, A. and PIETRASZEK, J. On the role of histomorphometric (stereological) microstructure parameters in the prediction of vertebrae compression strength. Image Analysis and Stereology. 2019, vol. 38, pp.63-73. 